\title{
Exploring Potential Risk Factors for Benign Vocal Fold Mucosal Disorders Using Weighted Logistic Regression
}

\author{
Haewon Byeon ${ }^{1,2}$ \\ ${ }^{1}$ Dept. of Speech Language Pathology \& Audiology, Nambu University, Gwangju, \\ South Korea \\ ${ }^{2}$ Speech-Language Pathology Center, Nambu University, Gwangju, South Korea, \\ byeon@nambu.ac.kr
}

\begin{abstract}
Although various factors such as misuse and abuse of vocal cord, occupation, smoking have been reported to be associated with benign vocal fold mucosal disorders, there have been few studies that have taken into consideration all factors of social demographic influences, health-risk behaviors and self-reported voice problems. This study explores potential risk factors of benign vocal fold mucosal disorders for 1,127 adults (468 males and 659 females) over the age of 19 who completed Korea National Health and Nutrition Examination Survey in 2012.

Weighted logistic regression model was used for analysis. When compounding factors were adjusted, the association with benign vocal fold mucosal disorders was 6.8 times higher for high school graduates and 6 times higher for university graduates ( $p<0.05)$. In addition, the association with benign vocal fold mucosal disorders was 5.8 times higher for those with self-reported voice problems $(p=0.001)$. Thus, it is necessary to monitor those with selfreported voice problems in early stages to prevent benign vocal fold mucosal disorders.

These results might be used as basic material for the prevention of benign vocal fold mucosal disorders. Future longitudinal studies are required to better understand the causality between self-reported vocal problems and actual benign vocal fold mucosal disorders.
\end{abstract}

Keywords: Dysphonia, Benign vocal fold mucosal disorders, Risk factors, Prevention

\section{Introduction}

Benign vocal fold mucosal disorders such as vocal nodules, laryngeal polyps, intracordal cysts, Reinke's edema, laryngeal granuloma, glottic sulcus, and laryngeal keratosis are gathered together under the generic term "benign vocal fold mucosal disorders," which refers to benign tissues in the laryngeal mucosa, and are typical reasons for dysphonia [1-2]. In 2005, the prevalence rate of dysphonia in the Unites States recorded as 6.6\%.It has been reported that this problem appears more frequently with age [3-4]. Approximately 10\% of the U.S population has experienced dysphonia and it is estimated that the social cost incurred by problems such as unemployment caused by dysphonia amount to $\$ 2.5$ billion USD each year for the teaching occupation alone [5].

The reasons for benign vocal fold mucosal disorders, as far as is known, are as diverse as the misuse and abuse of the vocal cords, excessive smoking and drinking, damage to larynx from repeated coughing, acid reflux, injury of the laryngeal mucosa, infection of the upper airway, vitamin deficiency, and laryngeal inflammatory disorders [6-8]. Healthy habits are critical in the rehabilitation process of benign vocal fold mucosal disorders, and if the causal factors that have influenced the voice are not eliminated even after successful operations, 
patients run a high risk of suffering relapses. In addition, laryngeal keratosis, one type of benign vocal fold mucosal disorders, has an unfortunately high tendency to develop into laryngeal cancer, prevention of benign vocal fold mucosal disorders reduces the possibility of laryngeal cancer [6].

Although such benign vocal fold mucosal disorders as vocal nodules and laryngeal polyps are voice disorders most frequently contracted by adults, so far studies on risk factors for benign vocal fold mucosal disorders in Koreans have been insufficient.

This study investigated the potential risk factors of benign vocal fold mucosal disorders using the otolaryngological examination data from the 2012 Korea National Health and Nutrition Examination Survey (KNHANES).

\section{Methods}

\subsection{Study Subjects}

The subjects of this study was adults 19 years and older who participated in the otolaryngological survey from the KNHANES in 2012.The KNHANES is a nationwide representative survey with a complex, stratified, multistage design to assess the health and nutritional status of the non-institutionalized population in Korea. The 2012 survey was conducted on a total of 10,069 persons out of 3,800 households. The participation rate was $80 \%(\mathrm{n}=8,057)$ [11].This study selected as subjects 1,335 persons who had completed both the questionnaire survey on health and an endoscopic laryngeal examination, of whom 208 persons were excluded because the results of their endoscopic laryngeal examinations were illegible, leaving us with a total of 1,127 persons (468 males and 659 females) as the final subjects of study.

\subsection{Measurement}

Among Questionnaire Survey on Health, survey on level of education and economic activity was conducted by individual interviews and survey on behaviors regarding health such as smoking, drinking and obesity was executed with self-administered questionnaires from January to December in 2012. Endoscopic laryngeal examinations for laryngeal legions were performed by otolaryngologist with $70^{\circ}$ endoscope on male and female adults aged 19 and over.

\subsubsection{Benign Vocal Fold Mucosal Disorders}

Benign vocal fold mucosal disorders in this study were defined as vocal nodules, laryngeal polyps, intracordal cysts, reinke's edema, laryngeal granuloma, glottic sulcus and laryngeal keratosis Figure 1 [1-2].

\subsubsection{Socio-demographic Factors}

Ages were counted in full and classified into groups of 19 39, 40 59 and 60 and over. Occupations were surveyed based on Korean standard classification of occupations 6th revision [9], and classified into economically- inactive (unemployed persons, housewives and students), non-manual (managers, clerical workers, service \& sales workers) and manual (skilled agricultural \& forestry \& fishery workers, craft and related trades workers, elementary occupations). Levels of education were classified as elementary school graduates and lower, middle school graduates, high school graduates and university graduates and over. Levels of income for households were classified into four quartiles. 
(a) vocal nodules

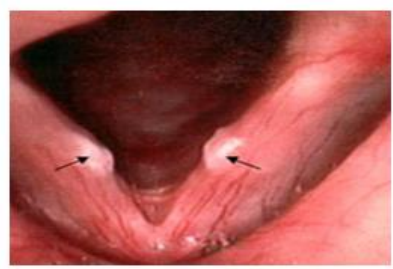

(d) reinke's edema

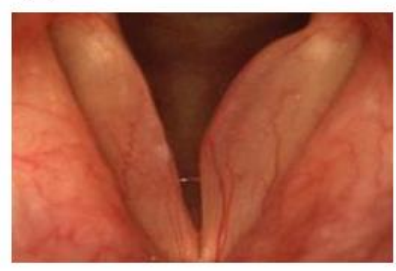

(g) laryngeal keratosis

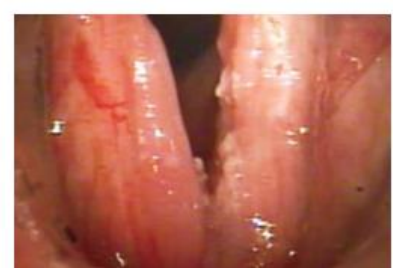

(b) laryngeal polyps

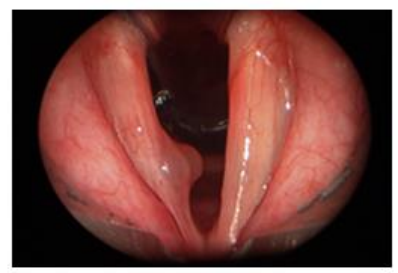

(e) laryngeal granuloma

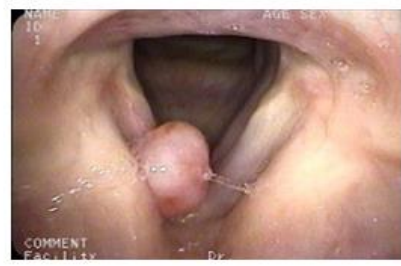

(c) intracordal cysts

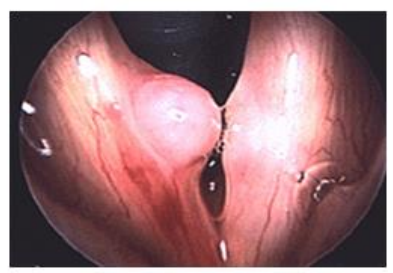

(f) glottic sulcus

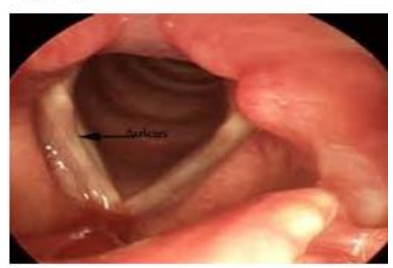

Figure 1. Type of Benign Vocal Fold Mucosal Disorders

\subsubsection{Health-risk Behavioral Factors}

Smoking was classified into current smokers, past smokers and non-smokers. Frequency of drinking was classified into less-than-once per week, 2 3 times per week and over 4 times per week. Based on Body Mass Index (BMI, $\mathrm{kg} / \mathrm{m}^{2}$ ) used as Asia-Pacific Standard of World Health Organization for Koreans, 18.5 and less was defined as under-weight, $18.5 \sim 24.9$ was defined as normal and 25 and over was defined as obese. Those who currently reported having problems with their voice were classified as having self-reported voice problems.

\subsection{Data Analysis}

All analyses were conducted based on complex sample design so that surveyed samples represent overall Korean population [10]. Weighted values of 2012 were set in such a way that individuals participating in the survey represent the population of Korea (See Formula).

$$
\widehat{X}=\sum_{i} w_{i} x_{i} / \sum_{i} w_{i}
$$

Detailed explanations on weighted values are elaborated in [11]. Rao-scott chi-square test was used to compare age, gender, the level of education and occupation of normal group and of those with benign vocal fold mucosal disorders. In order to identify potential risk factors for benign vocal fold mucosal disorders, odds ratio and 95\% confidence interval were presented by using weighted logistic regression analysis. SPSS version 20.0 (IBM Inc., Chicago, Illinois) was used for all analyses. 


\section{Results}

\subsection{General Characteristics of Population}

The General characteristics of population are presented in Table 1. The result of descriptive analysis applying weighted values, surveyed age groups were composed $39.6 \%$ of persons 19-39 years of age, $40.3 \%$ who were $40-59$ and $20.1 \%$ who were 60 or older. Gender was split $48.6 \%$ male and $51.4 \%$ female. As for listed occupation, the percentage of people who were classed as unemployed, which included such occupations as housewives and students was the highest at $38.3 \%$. Non-smokers made up 53.6\% of the people surveyed, and $72.1 \%$ drank alcohol less than once a week. The obesity rate was $34.1 \%$ and those with a selfreported vocal problem were $8.1 \%$.

Table 1. General Characteristics of Population $(n=1,127)$

\begin{tabular}{|c|c|}
\hline Characteristics & weighted \% \\
\hline \multicolumn{2}{|l|}{$\overline{\text { Age }}$} \\
\hline 19 39 & 39.6 \\
\hline $40 \sim 59$ & 40.3 \\
\hline $60 \sim$ & 20.1 \\
\hline \multicolumn{2}{|l|}{ Sex } \\
\hline Male & 48.6 \\
\hline Female & 51.4 \\
\hline \multicolumn{2}{|l|}{ Education level } \\
\hline$\leq$ Elementary school & 18.1 \\
\hline Middle school & 11.2 \\
\hline High school & 40.4 \\
\hline$\geq$ College & 30.3 \\
\hline \multicolumn{2}{|l|}{ Income } \\
\hline Quartile 1 & 13.6 \\
\hline Quartile 2 & 28.4 \\
\hline Quartile 3 & 28.2 \\
\hline Quartile 4 & 29.9 \\
\hline \multicolumn{2}{|l|}{ Occupation* } \\
\hline Economically inactive & 38.3 \\
\hline Non-manual & 39.8 \\
\hline Manual & 21.9 \\
\hline \multicolumn{2}{|l|}{ Smoke } \\
\hline Non smoker & 53.6 \\
\hline Past smoker & 18.8 \\
\hline Current smoker & 27.6 \\
\hline \multicolumn{2}{|l|}{ Frequency of drinking } \\
\hline$\leq 1$ time per weeks & 72.1 \\
\hline 2-3 times per weeks & 19.8 \\
\hline$\geq 4$ times per weeks & 8.1 \\
\hline \multicolumn{2}{|l|}{ Self-reported voice problem } \\
\hline Yes & 8.1 \\
\hline \multicolumn{2}{|l|}{ BMl } \\
\hline Normal & 61.5 \\
\hline Under-weight & 4.4 \\
\hline
\end{tabular}




\begin{abstract}
* Economically inactive: an unemployed person, housewife, student; Non-manual: managers \& professionals, clerical support workers and service \& sales workers; Manual: skilled agricultural $\&$ forestry \& fishery workers, craft \& related trades workers and elementary occupations.
\end{abstract}

\title{
3.2. Characteristics of Subjects with Benign Vocal Fold Mucosal Disorders
}

The characteristics of subjects with benign vocal fold mucosal disorders are presented in Table 2. The highest prevalence rate of benign vocal fold mucosal disorders in each category was in the age group of $40-59(3.1 \%)$; females $(3.2 \%)$; high school graduates $(4.0 \%)$; past smokers $(3.4 \%)$;those who drank less than once per week (3.7\%); self-reported vocal problem $(10.6 \%)$; and the obese $(3.4 \%)$.

As the result of a Chi-square test, there was found to be a significant difference between the healthy group and the group with benign vocal fold mucosal disorders in the recognition of their own vocal problems $(p<0.001)$. The prevalence rate of benign vocal fold mucosal disorders for the group who recognized their own vocal problems was $10.6 \%$, which was five times higher than that of the group who didn't recognize their own vocal problems.

Table 2. Characteristics of Subjects with Benign Vocal fold Mucosal Disorders, Weighted \%

\begin{tabular}{|c|c|c|c|}
\hline Variables & Healthy $(n=1,094)$ & $\operatorname{BVD}(n=33)$ & $\mathrm{P}^{*}$ \\
\hline$\overline{\text { Age }}$ & & & $\overline{0.779}$ \\
\hline $19 \sim 39$ & 97.4 & 2.6 & \\
\hline $40 \sim 59$ & 96.9 & 3.1 & \\
\hline $60 \sim$ & 97.7 & 2.3 & \\
\hline Sex & & & 0.461 \\
\hline Male & 97.7 & 2.3 & \\
\hline Female & 96.8 & 3.2 & \\
\hline Income (home) & & & 0.896 \\
\hline Quartile 1 & 98.2 & 1.8 & \\
\hline Quartile 2 & 97.5 & 2.5 & \\
\hline Quartile 3 & 97.2 & 2.8 & \\
\hline Quartile 4 & 96.7 & 3.3 & \\
\hline Education level & & & 0.377 \\
\hline$\leq$ Elementary school & 98.5 & 1.5 & \\
\hline Middle school & 98.0 & 2.0 & \\
\hline High school & 96.0 & 4.0 & \\
\hline$\geq$ College & 97.5 & 2.5 & \\
\hline Occupation & & & 0.711 \\
\hline Economically inactive & 97.6 & 2.4 & \\
\hline Non-manual & 96.6 & 3.4 & \\
\hline Manual & 97.3 & 2.7 & \\
\hline Smoke & & & 0.879 \\
\hline Non smoker & 97.4 & 2.6 & \\
\hline Past smoker & 96.6 & 3.4 & \\
\hline Current smoker & 97.1 & 2.9 & \\
\hline
\end{tabular}




$\begin{array}{lrrr}\text { Frequency of drinking } & & & 0.275 \\ \quad \text { Abstainer } & 97.6 & 2.4 & \\ \text { s1 times per weeks } & 96.3 & 3.7 & \\ \quad \geq 2 \text { times per weeks } & 98.5 & 1.5 & <0.001 \\ \text { Self-reported voice problem } & & & \\ \quad \text { No } & 97.9 & 2.1 & 0.541 \\ \quad \text { Yes } & 89.4 & 10.6 & \\ \text { BMl } & & & \\ \quad \text { Normal } & 97.3 & 2.7 & \\ \text { Under-weight } & 100.0 & 0 & \\ \text { Obese } & 96.6 & 3.4 & \end{array}$

BVD=Benign vocal fold mucosal disorders

${ }^{*}$ Rao-scott chi-square test for complex sample

\subsection{Factors Related to Benign Vocal Fold Mucosal Disorders}

Odds ratios and confidence intervals of factors related to benign vocal fold mucosal disorders are presented in Table 3. In a crude model not adjusted for confounding factors, the factors most highly related to benign vocal fold mucosal disorders were the level of education and subjective recognition of vocal problem. High school graduates were 2.8 times $(\mathrm{OR}=2.79$, 95\% CI: 1.26-6.17) highly associated with benign vocal fold mucosal disorders than elementary school graduates $(\mathrm{p}<0.05)$. In addition, the association of those who subjectively recognized their own vocal problems with benign vocal fold mucosal disorders was 5.6 times $(\mathrm{OR}=5.60$, 95\% CI: 2.21-14.22) higher than those who did not recognize their own vocal problems $(\mathrm{p}=0.001)$.

In the model adjusted for all variables (age, gender, level of education, income level, occupation, obesity, smoking, drinking, and subjective recognition of vocal problem), the level of education and subjective recognition of vocal problem were also associated independently with benign vocal fold mucosal disorders (Figure 2). High school graduates were 6.2 times $(\mathrm{OR}=6.17,95 \% \mathrm{CI}$ : 1.85-25.23) more highly and university graduates were six times $(\mathrm{OR}=5.99,95 \%$ CI: 1.11-32.17) more highly associated (by odds ratio) with benign vocal fold mucosal disorders than elementary school graduates $(\mathrm{p}<0.05)$. In addition, the relationship between the existence of benign vocal fold mucosal disorders in those who subjectively recognized their own vocal problems was 5.8 times $(\mathrm{OR}=5.79$, 95\% CI: 2.2814.71) higher than those who did not recognize their own vocal problems $(\mathrm{p}=0.001)$. 
Table 3. Odds Ratios (OR) and Confidence Intervals (Cl) of Factors Related to Benign Vocal Fold Mucosal Disorders: Weighted Logistic Regression Model

\begin{tabular}{|c|c|c|c|c|c|c|c|c|}
\hline & \multicolumn{4}{|c|}{ Crude model } & \multicolumn{4}{|c|}{ Adjusted model } \\
\hline & \multirow[t]{2}{*}{$\overline{\text { OR }}$} & \multirow[t]{2}{*}{$p$} & \multicolumn{2}{|c|}{$95 \% \mathrm{Cl}$} & \multirow[t]{2}{*}{$\overline{\mathrm{OR}}$} & \multirow[t]{2}{*}{$p$} & \multicolumn{2}{|c|}{$95 \% \mathrm{Cl}$} \\
\hline & & & Low & High & & & Low & High \\
\hline Age & & 0.775 & & & & 0.589 & & \\
\hline (19 39) & & & & & & & & \\
\hline $40 \sim 59$ & 1.18 & & 0.41 & 3.44 & 1.58 & & 0.43 & 5.76 \\
\hline $60 \sim$ & 0.82 & & 0.35 & 2.15 & 1.99 & & 0.51 & 7.76 \\
\hline $\begin{array}{l}\text { Sex } \\
\text { (Male) }\end{array}$ & & 0.463 & & & & 0.293 & & \\
\hline Female & 1.43 & & 0.54 & 3.77 & 2.06 & & 0.52 & 8.15 \\
\hline $\begin{array}{l}\text { Education level } \\
\quad \text { ( } \leq \text { Elementary school) }\end{array}$ & & 0.041 & & & & 0.025 & & \\
\hline Middle school & 1.38 & & 0.24 & 8.00 & 3.48 & & 0.73 & 16.44 \\
\hline High school & 2.79 & & 1.26 & 6.17 & 6.84 & & 1.85 & 25.23 \\
\hline$\geq$ College & 1.71 & & 0.39 & 7.38 & 5.99 & & 1.11 & 32.17 \\
\hline $\begin{array}{l}\text { Income } \\
\text { (Quartile 1) }\end{array}$ & & 0.790 & & & & 0.992 & & \\
\hline Quartile 2 & 1.36 & & 0.22 & 8.51 & 0.91 & & 0.13 & 6.09 \\
\hline Quartile 3 & 1.58 & & 0.28 & 8.89 & 0.76 & & 0.11 & 4.98 \\
\hline Quartile 4 & 1.81 & & 0.54 & 6.02 & 0.95 & & 0.26 & 3.44 \\
\hline $\begin{array}{l}\text { Occupation } \\
\text { (Economically inactive) }\end{array}$ & & 0.086 & & & & 0.494 & & \\
\hline Non-manual & 1.45 & 0.912 & 0.47 & 4.47 & 1.70 & & 0.63 & 4.57 \\
\hline Manual & 1.15 & 0.806 & 0.47 & 2.84 & 1.75 & & 0.47 & 6.52 \\
\hline $\begin{array}{l}\text { Smoke } \\
\quad \text { (Non smoker) }\end{array}$ & & 0.911 & & & & 0.283 & & \\
\hline Past smoker & 1.29 & & 0.34 & 4.88 & 2.35 & & 0.53 & 10.38 \\
\hline Current smoker & 1.11 & & 0.47 & 2.59 & 2.05 & & 0.77 & 5.42 \\
\hline $\begin{array}{l}\text { Frequency of drinking } \\
\text { (Abstainer) }\end{array}$ & & 0.297 & & & & 0.546 & & \\
\hline$\leq 1$ times per weeks & 1.58 & & 0.56 & 4.45 & 1.14 & & 0.33 & 3.89 \\
\hline$\geq 2$ times per weeks & 0.61 & & 0.11 & 3.22 & 0.41 & & 0.03 & 4.51 \\
\hline $\begin{array}{l}\text { Self-reported voice } \\
\text { problem } \\
\text { (No) }\end{array}$ & & 0.001 & & & & 0.001 & & \\
\hline Yes & 5.60 & & 2.21 & 14.22 & 5.79 & & 2.28 & 14.71 \\
\hline $\begin{array}{l}\text { BMI } \\
\text { (Normal) }\end{array}$ & & 0.494 & & & & 0.663 & & \\
\hline Obese & 1.25 & & 0.50 & 3.13 & 1.05 & & 0.34 & 3.18 \\
\hline
\end{tabular}




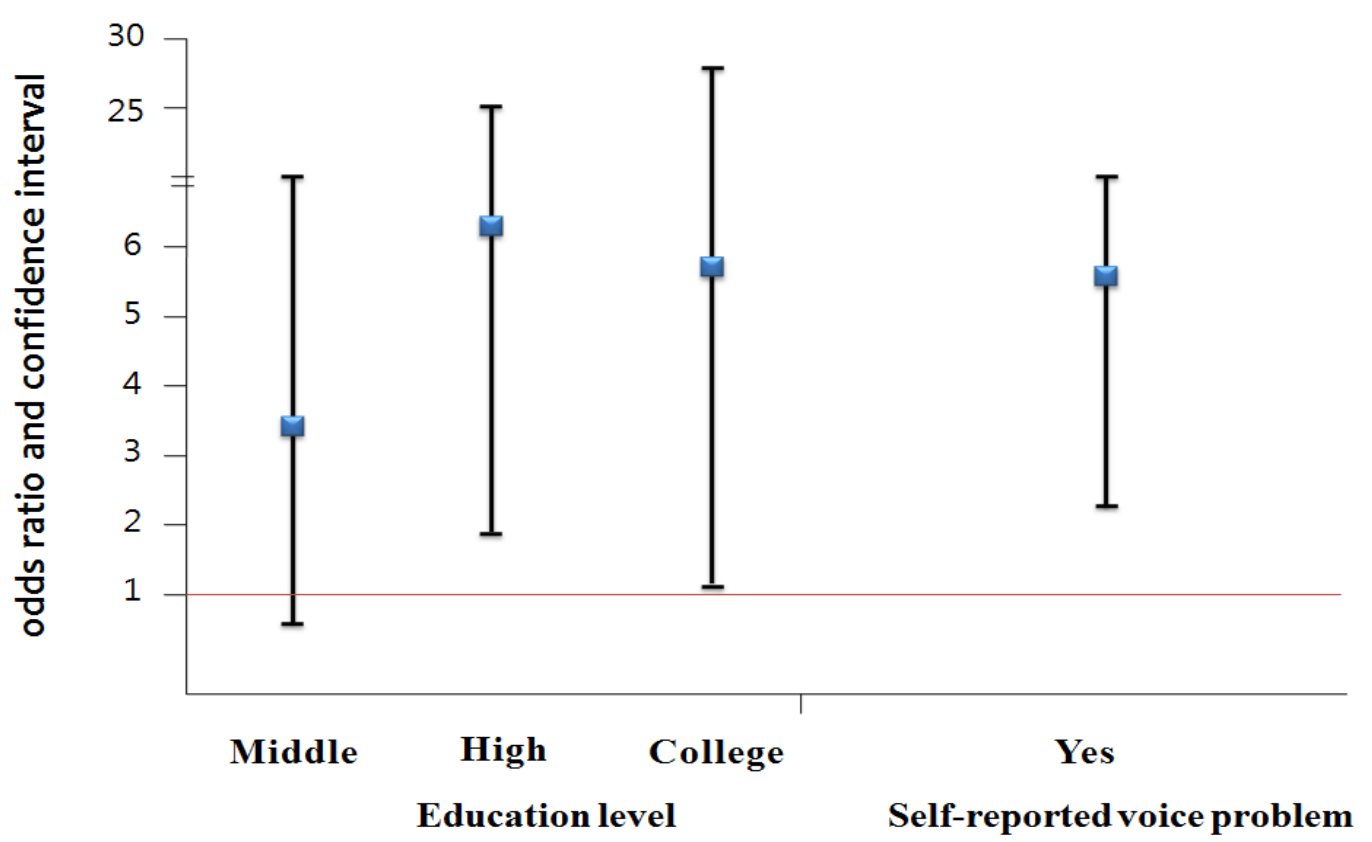

Figure 2. Adjusted Model of Factors Related to Benign Vocal Fold Mucosal Disorders

\section{Discussion}

In this study, health-risk behaviors such as smoking and drinking did not have a significant relationship with benign vocal fold mucosal disorders. Numerous clinical research studies have reported the negative influence of smoking and drinking on the larynx $[12,13]$. Smoking has not merely been proven to have a close relationship with the progression of chronic laryngitis, keratosis, and leukoplakia [14], but has also been confirmed to be a cause of the deformation of the mucosa of the vocal cord in animal experiments [15]. Furthermore, frequent drinking has been reported to increase the risk of laryngeal disorders by causing vasodilatation and edema in the mucosa of vocal cord [16]. Nevertheless, epidemiological study on population groups, all the factors of the period of smoking, the frequency and period of drinking, weekly amount of drinking, and starting age of drinking were not found to have an independent relationship with dysphonia [3, 22, 23]. Likewise, smoking and drinking were not found to have a relationship with benign vocal fold mucosal disorders in this study. The reason for this incongruity between clinical studies and this epidemiological study in the relationship of health-risk behaviors with laryngeal disorders is deemed to originate from the characteristics of the study subjects. Unlike the preceding studies $[12,13]$ that analyzed the vocal problems of particular groups, this cross-sectional study used big data that represented an overall population. Although the relationship of smoking and drinking with benign vocal fold mucosal disorders appeared insignificant in this study, it is necessary to confirm the relationship between health-risk behaviors and laryngeal legions in future longitudinal studies, since health-risk behaviors tend to have an effect on diseases in the long term.

In this study, the level of education appeared to have a significant relationship with benign vocal fold mucosal disorders. High school graduates were 6.2 times and university graduates were six times more highly associated with benign vocal fold mucosal disorders than elementary school graduates. Similar to this study, the study by Baylor et al., (2008) that 
analyzed the speech usage of 200 patients with spasmodic dysphonia, also reported a high rate of vocal problems for people with university degrees and above [17]. Despite this, there have been only a few studies that have analyzed the relationship of laryngeal disorders with the level of education and up until now clear mechanism of the relationship between the level of education and laryngeal disorders has not been disclosed, either. One possibility might be that groups with high level of education are more inclined to have occupations that require a greater use of their voice [17]. Teachers who overuse their voices, vocal performers, the clergy, and telemarketers have been reported to have high risk of voice disorders [18-19], and these occupations mostly require a high school diploma and above. As there have been few studies on the association of dysphonia with the level of education, various studies are required in the future that focus on the socio-economic characteristics of dysphonia.

Another potential risk factor of benign vocal fold mucosal disorders in this study turned out to be the subjective recognition of vocal problems. Those who recognized their own vocal problem in this study ran a 5.8 times higher risk of developing benign vocal fold mucosal disorders. In the study of Roy et al., (2007), discomfort while using their voice also proved to be one of major precursors of vocal problems in the results of this study [20]. In addition, it is known that vocal tract discomfort has a relationship with symptoms of early vocal disorders [21]. Prospective studies are required to prove causality between subjective recognition of vocal problems and benign vocal fold mucosal disorders in the future.

The strength of this study is that it analyzed the potential risk factors of benign vocal fold mucosal disorders using the national statistical data that represented Koreans in local communities.

The limitations of this study are as follows: First, as this study is cross-sectional, it is difficult to make causal assumptions. Thus, a future longitudinal study is required to explore causality. Second, since the health survey for this study was conducted with self-administered questionnaires, there exists the possibility that subjects may have chosen less extreme answers for negative items than the truth, which would require careful interpretation and application of the study results.

It is necessary to perform accurate consultations with patients as well as precise operations and extensive voice rehabilitation to successfully manage vocal cord lesions. This study can be used as solid foundational material in the course of consultation and examination for the prevention of vocal problems and the prevention of their recurrence in the fields of vocal treatment. Moreover, the results of this study imply the importance of preventing benign vocal fold mucosal disorders.

\section{Acknowledgements}

The author would like to acknowledge the Korea Center for Disease Control and Prevention that provided the raw data for analysis.

\section{References}

[1] Medical Research and Training Institute, Family Medicine, Seoul National University, Seoul (1998).

[2] P. W. Flint, B. H. Haughey, V. J. Lund, J. K. Niparko, M. A. Richardson, K. T. Robbins and J. R. Thomas, Cummings Otolaryngology: Head and Neck Surgery, Mosby Elsevier, Pennsylvania (2010).

[3] N. Roy, R. M. Merrill, S. D. Gray and E. M. Smith, Voice disorders in the general population: prevalence, risk factors, and occupational impact. Laryngoscope, vol. 115, (2005), pp. 1988-1995.

[4] B. L. Herrington-Hall, L. Lee, J. C. Stemple, K. R. Niemi and M. M. McHone, "Description of laryngeal pathologies by age, sex, and occupation in a treatment-seeking sample", Journal of Speech, Hearing Disorders, vol. 53, (1988), pp. 57-64.

[5] K. Verdolini and L. O. Ramig, "Review: occupational risks for voice problems", Logopedics Phoniatrics Vocology, vol. 26, (2001), pp. 37-46. 
[6] D. Boone, S. C. McFarlane and S. L. Von Berg, The voice and voice therapy: (7th ed.), Allyn \& Bacon, Boston (2004).

[7] A. K. Lalwani, "Current diagnosis and treatment in otolaryngology-head and neck surgery: (2ed ed.), McGraw-Hill Medical, New York (2007).

[8] J. H. Chung, K. Tae, Y. S. Lee, J. H. Jeong, S. H. Cho, K. R. Kim, C. W. Park and D. S. Han, "The significance of laryngopharyngeal reflux in benign vocal mucosal lesions", Otolaryngology-Head and Neck Surgery, vol. 141, (2009), pp. 369-373.

[9] Korea National Statistical Office, Korean standard classification of occupations 6th revision, Korea national statistical office, Daejeon, (2007).

[10] H. Byeon, "Comparative analysis of unweighted sample design and complex sample design related to the exploration of potential risk factors", Korea Acad Industr Coop Soc, vol. 13, (2012), pp. 2251-2258.

[11] Korea Centers for Disease Control and Prevention, The Korea national health and nutrition examination survey 2012, Korea Centers for Disease Control and Prevention, Seoul, (2013).

[12] R. H. Feierabend and M. N. Shahram, "Hoarseness in adults", American Family Physician, vol. 80, (2009), pp. 363-370.

[13] A. Altieri, C. Bosetti, R. Talamini, S. Gallus, S. Franceschi, F. Levi, L. Dal Maso, E. Negri and C. La Vecchia, "Cessation of smoking and drinking and the risk of laryngeal cancer", British Journal of Cancer , vol. 87, (2002), pp. 1227-1229.

[14] I. Syed, E. Daniels and N. R. Bleach, "Hoarse voice in adults: an evidence-based approach to the 12 minute consultation", Clinical otolaryngology, vol. 34, (2009), pp. 54-58.

[15] J. L. Duarte, F. A. de Faria, D. S. Ceolin, T. M. Cestari and G. F. de Assis, "Effects of passive smoke inhalation on the vocal cords of rats", Brazilian journal of otorhinolaryngology, vol. 72, (2006), pp. 210-216.

[16] K. Kjaerheim, M. Gaard and A. Andersen, "The role of alcohol, tobacco and dietary factors in upper aerogastric tract cancers: a prospective study of 10,900 Norwegian men”, Cancer Causes Control, vol. 9, (1998), pp. 99-108.

[17] C. Baylor, K. Yorkston, T. Eadie, R. Miller, D. Amtmann, "Levels of speech usage: a self-report scale for describing how people use speech", J Med Speech Lang Pathol, vol. 16, (2008), pp. 191-198.

[18] S. Sapir, A. Keidar and B. Marthers-Schmidt, "Vocal attrition in teachers: survey findings", European Journal of Disorders of Communication, vol. 4, (1993), pp. 223-244.

[19] E. Smith, M. Gray, S. Dove, L. Kirchner and H. Heras, "Frequency and effects of teachers voice problems", Journal of Voice, vol. 11, (1997), pp. 81-87.

[20] N. Roy, J. Stemple, R. M. Merrill and L. Thomas, "Epidemiology of voice disorders in the elderly: preliminary findings", Laryngoscope, vol. 117, (2007), pp. 628-633.

[21] G. Rodrigues, F. Zambon, L. Mathieson and M. Behlau, "Vocal tract discomfort in teachers: its relationship to self-reported voice disorders", Journal of Voice, vol. 27, (2013), pp. 473-480.

[22] H. Byeon and Y. Lee, "Laryngeal pathologies in older Korean adults and their association with smoking and alcohol consumption", Laryngoscope, vol. 123, (2013), pp. 429-433.

[23] H. Byeon, "Related risk factors for benign laryngeal lesions in community-dwelling Korean adults: a cross sectional study", Advanced Science and Technology Letters, vol. 47, (2014), pp. 328-330.

\section{Author}

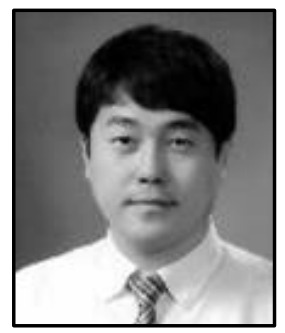

Haewon Byeon, he received the DrSc degree in Biomedical Science from Ajou University School of Medicine. He is a professor in Department of Speech Language Pathology \& Audiology and director of Speech Language Pathology Center in Nambu University. His recent interests focus on health promotion and biostatistics. 